\title{
Hormonal Regulation of Membrane Phenotype
}

\author{
Sarah A. Carlson and Thomas D. Gelehrter \\ Departments of Human Genetics and Internal Medicine, University of Michigan Medical \\ School, Ann Arbor, Michigan 48109
}

\begin{abstract}
Incubation of rat hepatoma cells (HTC) in tissue culture with glucocorticoids alters several membrane properties characteristic of transformed cells, without affecting the growth rate of these cells. Variant cell lines resistant to dexamethasone inhibition of plasminogen activator production have been isolated using an agar-fibrin overlay technique to detect plasminogen activator production by individual colonies of HTC cells. The resistance to dexamethasone is not secondary to abnormal or absent glucocorticoid receptors, but due to a lesion in a later step in hormone action specific for plasminogen activator. These variants should prove useful for the study of the mechanism of steroid action as well as for the analysis of the role of proteases in the hormonal regulation of membrane function.
\end{abstract}

Key words: plasminogen activator, hepatoma cells, transformed membrane phenotype, glucocorticoid-resistant variants, glucocorticoids, amino acid transport, hormonal regulation, glucocorticoid regulation

Neoplastic transformation is associated with structural and functional alterations in the cell membrane which may have an important role in growth regulation. Hormones can also affect membrane phenotype in a manner similar or opposite to neoplastic transformation $(1,2)$. In $\mathrm{HTC}^{1}$ cells, an established line of rat hepatoma cells in tissue culture, glucocorticoids alter several membrane properties characteristic of transformed cells, but do not affect the growth rate of these cells. Dexamethasone, a synthetic glucocorticoid, a) rapidly and reversibly inhibits the rate of influx of selected amino acids by a process requiring concomitant protein synthesis ${ }^{2}(3)$; b) decreases the number of microvilli on the surface of HTC cells in suspension culture, as assessed by scanning electron microscopy; and c) increases the adhesiveness of HTC cells (4). Dexamethasone also decreases the production of plasminogen activator (5), an intracellular protease which may significantly modulate various membrane properties. Using an agar-fibrin overlay technique to detect plasminogen activator production by individual colonies of HTC cells (6), we have selected lines of HTC cells resistant to the inhibitory effect of dexamethasone. Combined genetic and biochemical analysis of such dexamethasone-resistant variants should facilitate study of hormonal regulation of specific membrane phenotypes.

\footnotetext{
${ }^{1}$ Abbreviations: HTC - hepatoma tissue culture; AIB - $\alpha$-aminoisobutyric acid; BSA - bovine serum albumin.

${ }^{2}$ McDonald, R. A. and Gelehrter, T. D., submitted for publication.
}

Received April 1, 1977 ; accepted April 27, 1977.

(C) 1977 Alan R. Liss, Inc., 150 Fif th Avenue, New York, NY 10011 


\section{AGAR-FIBRIN OVERLAY TECHNIQUE}

\section{PREPARATION OF AGAR-FIBRIN}

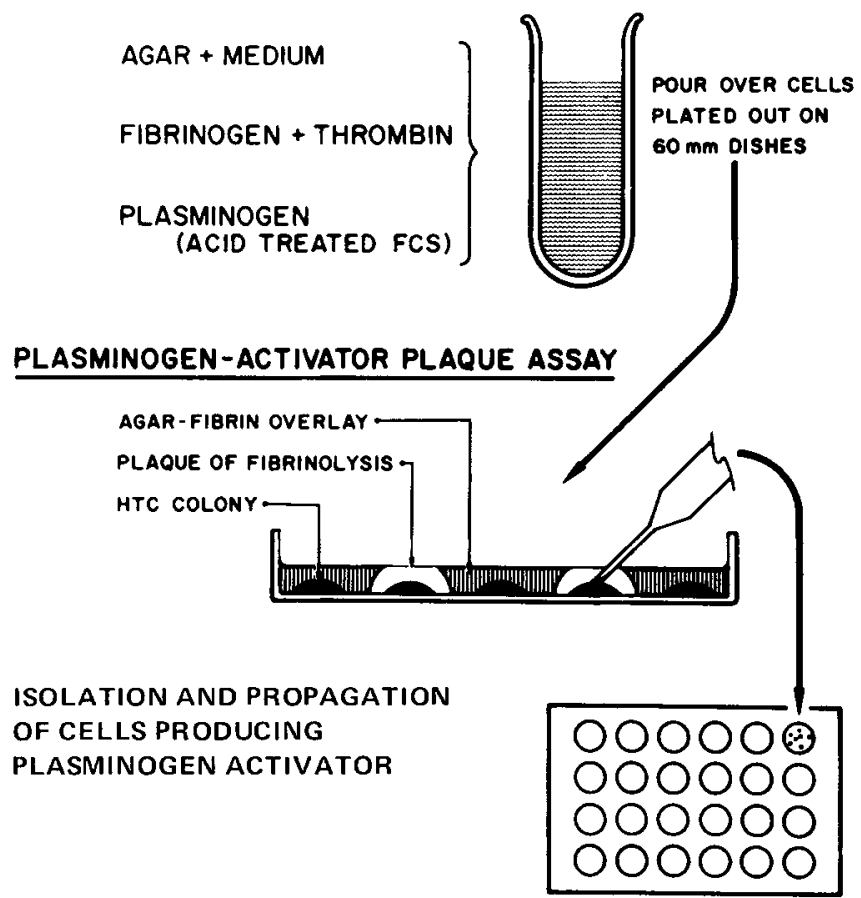

Fig. 1. Agar-fibrin overlay.

\section{METHODS}

HTC cells are an established line of rat hepatoma cells which have been in continuous culture for the past 12 years (7). The cells were grown in spinner culture without antibiotics in Eagle's minimal essential medium (MEM) for suspension culture, modified to contain $0.05 \mathrm{M}$ Tricine, $0.5 \mathrm{~g} /$ liter $\mathrm{NaHCO}_{3}, 2 \mathrm{mM}$ glutamine, $5 \%$ calf serum, and $5 \%$ fetal calf serum.

An agar-fibrin overlay technique (6) was used to detect the production of plasminogen activator by individual colonies (Fig. 1). HTC cells (100-200 cells per dish) were plated in $60-\mathrm{mm}$ tissue culture dishes in alpha-MEM (Flow Laboratories) without added hormones, supplemented with $10 \%$ fetal calf serum, and allowed to grow in to colonies for 5-7 days. The cells were then incubated overnight in serum-free MEM with or without $0.1 \mu \mathrm{M}$ dexamethasone. The plates were washed with serum-free medium, covered with $1.4 \mathrm{ml}$ of $0.9 \%$ agar containing $0.7 \times$ medium, $2.8 \mathrm{mg} / \mathrm{ml}$ fibrinogen, $1 \mathrm{U} / \mathrm{ml}$ thrombin, $3.6 \%$ acid-treated fetal calf serum (as a source of plasminogen), and with or without $1 \mu \mathrm{M}$ dexamethasone, and incubated at $37^{\circ} \mathrm{C}$ for $24 \mathrm{~h}$. The thrombin activates the fibrinogen to form fibrin, and an opalescent, fibrin meshwork is formed in the agar. Colonies producing plasminogen activator activate the plasminogen to plasmin, which in turn lyses the fibrin, and a clear area, or plaque, is formed. This technique is not destructive and allows recovery of selected colonies through the agar overlay, and their propagation. 


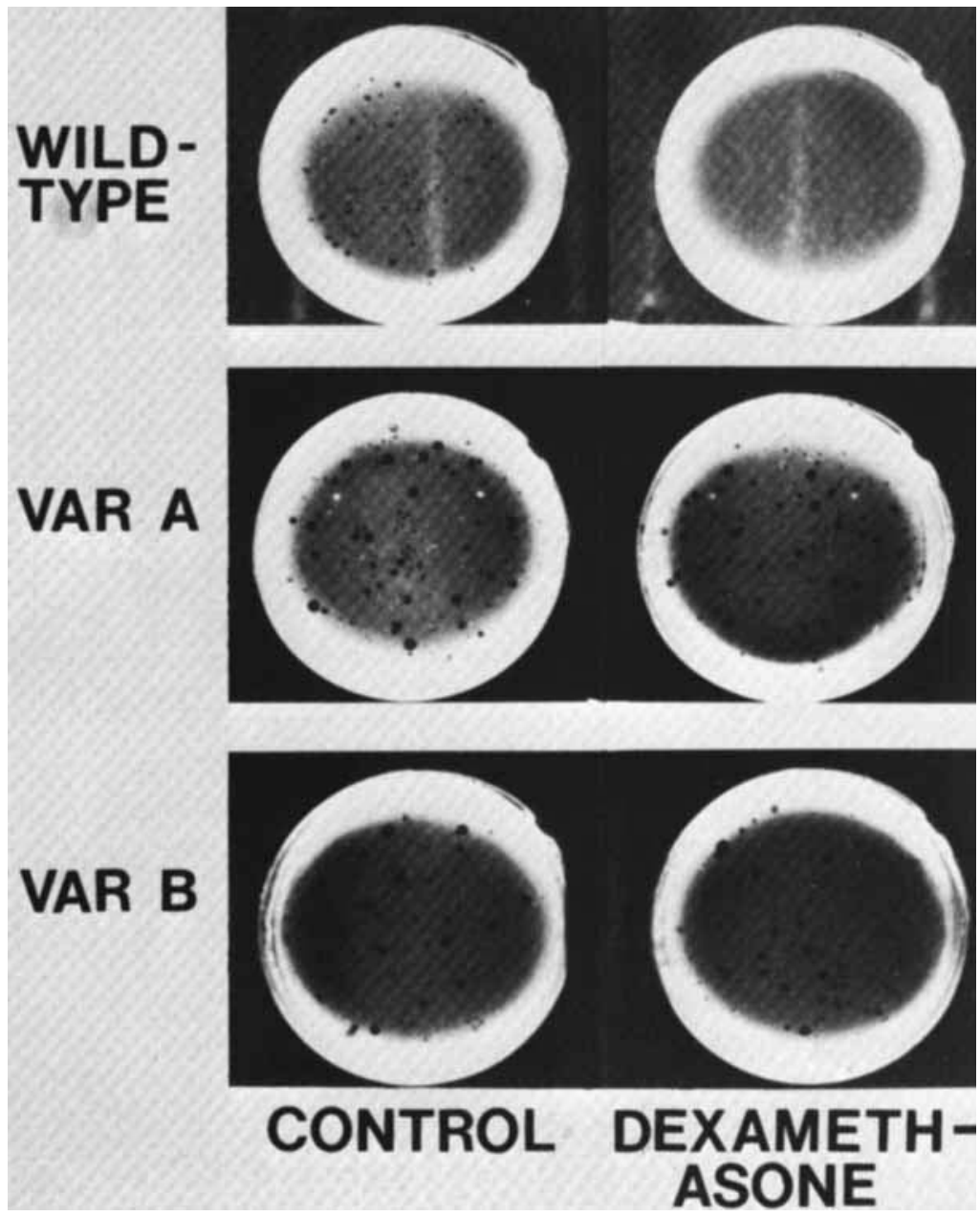

Fig. 2. HTC cells were plated in dilute suspension and allowed to grow in to colonies. The cells were incubated for $22 \mathrm{~h}$ in serum-free medium with or without $0.1 \mu \mathrm{M}$ dexamethasone. The plates were then covered with the agar-fibrin overlay in the continued presence or absence of dexamethasone $(1 \mu \mathrm{M})$ and photographed after $24 \mathrm{~h}$ incubation at $37^{\circ} \mathrm{C}$.

Transport of $\alpha$-aminoisobutyric acid (AIB) was measured as described by Heaton and Gelehrter (8). Tyrosine aminotransferase was assayed by the method of Spencer aid Gelehrter (9).

Fibrinogen (77\% clotable) was purchased from Calbiochem and purified as described by Strickland and Beers (10). Bovine thrombin was purchased from Parke-Davis. Dexamethasone was a gift from Merck and Company. All other compounds were of reagent grade.

\section{RESULTS}

The effect of dexamethasone on plasminogen activator production in HTC cells is shown in the upper portion of Fig. 2. In the absence of dexamethasone, 100\% of the colonies produced fibrinolytic plaques. After 18--24-h incubation in the presence of 0.1 


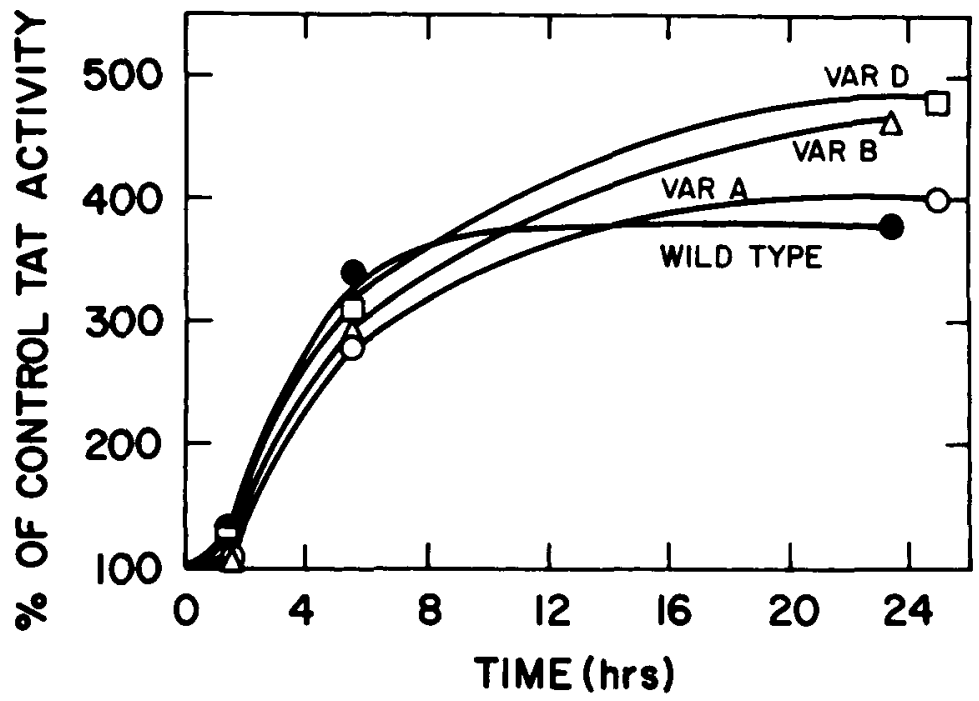

Fig. 3. Wild-ty pe and variant HTC cells were incubated in suspension culture in serum-free medium with $0.1 \%$ BSA with or without $0.1 \mu \mathrm{M}$ dexamethasone. At the times indicated, samples were taken for assay of tyrosine aminotransferase (9).

$\mu \mathrm{M}$ dexamethasone, less than $1 \%$ of the colonies produced plaques and most of these tended to be smaller than those produced in the absence of dexamethasone.

\section{Isolation of Dexamethasone-Resistant Variants}

Because dexamethasone inhibits plasminogen activator production, colonies which are resistant to dexamethasone inhibition should continue to produce plasminogen activator in the presence of the hormone. Hormone-resistant colonies will thus form plaques in the agar overlay in the presence of dexamethasone. Recovery of such plaque-forming colonies and retesting by the overlay technique has resulted in the isolation of populations of cells partially resistant to the inhibitory effects of dexamethasone on plasminogen activator production. By repeating (3-5 times) the process of isolation of plaque-forming colonies, serial propagation in the absence of dexamethasone, and retesting by the overlay technique, we have isolated a number of HTC cell lines fully resistant to the inhibitory effect of dexamethasone on protease production. The effect of dexamethasone on plasminogen activator production in 2 of these variants is shown in the lower portion of Fig. 2. Essentially all of the colonies of variants $\mathrm{A}$ and $\mathrm{B}$ produce plaques in the presence as well as the absence of dexamethasone, and the size of the plaques under the 2 conditions is the same.

\section{Analysis of Dexamethasone-Resistant Variants}

The basis for the hormonal resistance in these variant cell lines has been examined by testing for the presence of normal dexamethasone receptor function. This has been accomplished by the simple expedient of testing whether these lines have dexamethasone- 


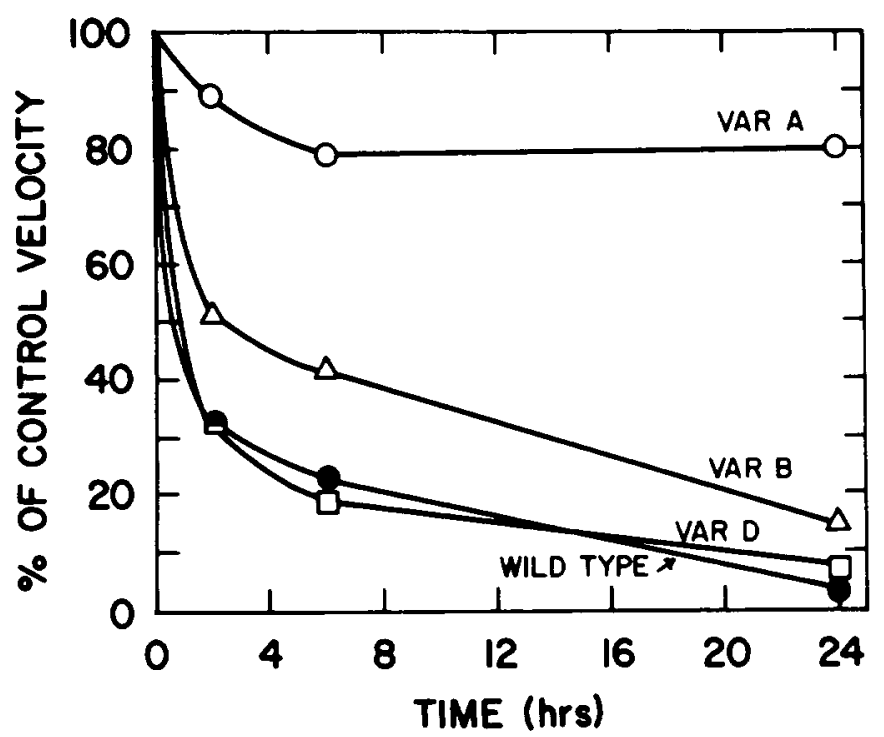

Fig. 4. Wild-type and variant HTC cells were incubated in suspension culture in serum-free medium with $0.1 \% \mathrm{BSA}$ with or without $0.1 \mu \mathrm{M}$ dexamethasone. At the times indicated, samples were taken for measurement of AIB transport (8).

inducible tyrosine aminotransferase, a well-characterized, non-membrane-associated response to glucocorticoids in HTC cells. Transaminase induction requires binding of the glucocorticoid to a specific cytoplasmic receptor, and translocation of the steroid-receptor complex to the nucleus where it interacts with nuclear chromatin, resulting in accumulation of specific messenger RNA (11). Furthermore, it is generally accepted that all glucocorticoid actions in a given cell are mediated by a single class of receptors $(11,12)$. As shown on Fig. 3, all variants tested (including 3 other lines not shown) show normal wild-type induction of tyrosine aminotransferase, unequivocally demonstrating normal glucocorticoid receptor function.

The specificity of the hormonal resistance in these variant lines has been tested by examining the ability of dexamethasone to alter other aspects of the transformed membrane phenotype. Figure 4 shows the effect of dexamethasone on AlB transport in wildtype and hormone-resistant HTC cells. Variants B and D, and all but $l$ of the other lines tested, show wild-type inhibition of AIB transport. In contrast, variant A appears to be pleiotropic, in that it shows at least partial resistance to the inhibitory effects of dexamethasone on AIB transport.

\section{DISCUSSION}

HTC cells provide a useful model for studying the hormonal regulation of membrane phenotype in neoplastic cells. Several membrane properties are modulated by glucocorticoids, without changing the growth rate of these cells. The hormonal responsiveness of this 
cell line has been extensively characterized. In order to study the mechanisms by which hormones regulate membrane phenotype, it would be useful to have variants resistant to specific hormone-mediated events. We report here the isolation of several, spontaneously occurring variant cell lines which are resistant to the dexamethasone inhibition of plasminogen activator production. The resistant phenotype of these variants has remained stable for 6-9 months (more than 100 generations) in culture in the absence of dexamethasone.

The resistance to dexamethasone is not secondary to abnormal or absent glucocorticoid receptors. All variants tested show wild-type induction of tyrosine aminotransferase, unequivocally demonstrating the presence of normal glucocorticoid receptor function. The lesion in these variants is presumably in some more distal step in hormone action, after the binding of hormone-receptor complexes to nuclear chromatin. This finding is in contrast to the great majority of glucocorticoid-resistant variants described previously. In mouse lymphoma lines, for example, essentially all variants which have been analyzed show deficient or defective glucocorticoid receptor (12). A probable exception to this situation is the recent report by Thompson et al. (13) describing the isolation of variant HTC cells in which tyrosine aminotrasferase is not inducible by dexamethasone, and in which glucocorticoid receptor function appears to be normal.

HTC cells resistant to the dexamethasone inhibition of plasminogen activator production should prove useful in the analysis of the role of proteases in the hormonal regulation of membrane phenotype. It is possible that dexamethasone regulation of membrane characteristics is secondary to a proteolytic removal or alteration of membrane proteins. It seems clear however that the inhibition of AIB transport is not secondary to an inhibition of plasminogen activator production since variants resistant to the latter effect retain normal inhibition of transport. On the other hand, it is quite possible that the dexamethasone induction of adhesiveness in HTC cells is secondary to the decrease in protease activity which in turn would allow the accumulation of specific glycoproteins involved in adhesion (14). This hypothesis is directly testable using the dexamethasone-resistant variants described in this report. The use of such variants should provide a powerful alternative to the use of protease inhibitors in the analysis of the role of proteases in regulation of membrane function; the problems associated with the latter approach have been critically reviewed (15). Finally, these variants should also provide a useful tool for the study of the mechanism by which dexamethasone regulates plasminogen activator production. Isolation of other variant cell lines resistant to specific hormone-mediated functions affecting different membrane properties should prove similarly useful.

\section{ACKNOWLEDGMENTS}

We thank Dr. Sidney Strickland for assistance with establishing the agar-overlay technique. This research was supported by National Institutes of Health Grant GM 15419. S.A.C. is supported by a predoctoral training grant from the National Institutes of Health, 5-T01-GM00071. T.D.G. is the recipient of a Faculty Research Award from the American Cancer Society.

\section{REFERENCES}

1. Holley RW: Nature 258:487, 1975.

2. Hsie AW, Jones C, Puck TT: Proc Natl Acad Sci USA 68:1648, 1971.

3. Risser WL, Gelehrter TD: J Biol Chem 248: 1248, 1973. 
4. Ballard P, Tomkins GM: J Cell Biol 47:222, 1970.

5. Wigler M, Ford JP, Weinstein IB: In Reich E, Rifkin D, Shaw E (eds): "Proteases and Biological Control." New York: Cold Spring Harbor Laboratory, 1975, p 849.

6. Jones P, Benedict W, Strickland S, et al: Cell 5:323, 1975.

7. Thompson EB, Tomkins GM, Curran JF : Proc Natl Acad Sci USA 56:296, 1966.

8. Heaton JH, Gelehrter TD: J Biol Chem 252:2900, 1977.

9. Spencer CJ, Gelehrter TD: J Biol Chem 249:577, 1974.

10. Strickland S, Beers WH: J Biol Chem 251:5694, 1976.

11. Rousseau GG: J Steroid Biochem 6:75, 1975.

12. Yamamoto KR, Gehring U, Stampfer MR, et al: Rec Prog Horm Res 32:3, 1976.

13. Thompson EB, Aviv D, Lippman ME: Endocrinology 100:406, 1977.

14. Pouyssegur JM, Pastan I: Proc Natl Acad Sci USA 73:544, 1976

15. Roblin R, Chou I-N, Black PH: Adv Cancer Res 22:203, 1975. 